\title{
Evaluation and Prognostication of Water Situation of Beijing-Tianjin-Hebei Region
}

\author{
Xueer Bai \\ North China Electric Power University, Baoding 071000, China \\ 523630491@qq.com
}

Keywords: $\quad$ water scarcity, Grey Model, Time Series Model, Logistic Model

\begin{abstract}
With about one quarters of the world's population experiencing water scarcity, our planet seems to be thirstier and thirstier. In this article, with necessary dynamic factors considered, an integrated model is built to evaluate the capacity of Beijing-Tianjin-Hebei region to supply clean water to meet demand of its population, and to forecast the water situation in 15 years as well.
\end{abstract}

\section{Introduction}

To analyze the water situation, the author started with water supply and demand. Since both of them are made up of various dynamic elements, the author build a Section Forecasting Model projecting every variable elements first and integrating them together in the end.

\section{Model building and analysis}

\section{Maximum available clean water supply}

The water supply consists of available water resources (AW) and diversion from other areas

(D).

Available water resources (AW) includes surface water and ground water. According to 【4】, there is a considerable multiple correlation between the annual precipitation, the average annual temperature and available water resources. We can get the trend of water resources through fitting.

$$
\mathrm{AW}=-27.1997+0.6081 \times \text { pre }-9.204 \times \mathrm{T}
$$

$\mathrm{T}$ : the annual average temperature of this region

pre: the annual average precipitation of this region

Diversion from other areas (D) is mainly considered the amount of diversion from South-to-North Water Diversion Project, which increases by $1.533 \times 10^{8} \mathrm{~m}^{3}$ each year. It can be expressed as

$$
\mathrm{D}=D_{0}+1.533\left(t-t_{0}\right)
$$

To sum up, total clean water supply of this region (P) can be expressed as follows:

$$
P=A W \times \rho_{1}+D
$$

$\rho_{1}$ is the utilization ratio of AW. Here we adopt $\rho=0.581$ after consulting.

\section{Precipitation forecasting}

The author use Time Series Forecasting Method to predict the trend of the annual precipitation for its periodicity. The period of motion of sunspot is 11 years. Considering the connections between sunspot and precipitation, the period of the annual precipitation is adopted as 11 years.

In general, for a sequence with a period of $s$, differential operation can be carried out first.

$$
\begin{aligned}
& \nabla_{s} X_{t}=\left(1-B^{s}\right) X_{t} \\
& \nabla_{s}^{d}=\left(1-B^{s}\right)^{d} X_{t}
\end{aligned}
$$

Based on this, then we can conduct ARMA model (Auto Regressive Moving Average Model).

Assume $\left\{X_{t}, t=0, \pm 1, \pm 2, \ldots\right\}$ is a zero mean value stationary series, then it can fit in the following model:

$$
X_{t}-\varphi_{t} X_{t-1}-\cdots-\varphi_{p} X_{t-p}=\varepsilon_{t}-\theta_{1} \varepsilon_{t-1}-\cdots-\theta_{q} \varepsilon_{t-q}
$$

In this equation, $\varepsilon_{t}$ is the stationary white noise whose zero mean value and variance is $\sigma_{\varepsilon}^{2}, X_{t}$ is a ARMA series whose order is $\mathrm{p}$, q. 
Apply operator polynomial $\varphi(B), \theta(B)$, equation (6) can be written as

$$
\varphi(\mathrm{B}) X_{t}=\theta(\mathrm{B}) \varepsilon_{t}
$$

For general stationary series $\left\{X_{t}, t=0, \pm 1, \pm 2, \ldots\right\}$, we assume its mean value $\mathrm{E}\left(X_{t}\right)=\mu$, then the following model can be satisfied:

$$
\left(X_{t}-\mu\right)-\varphi_{1}\left(X_{t-1}-\mu\right)-\cdots-\varphi_{p}\left(X_{t-p}-\mu\right)=\varepsilon_{t}-\theta_{1} \varepsilon_{t-1}-\cdots-\theta_{q} \varepsilon_{t-q}
$$

In this equation, $\varepsilon_{t}$ is the stationary white noise whose zero mean value and variance is $\sigma_{\varepsilon}^{2}$.

Utilizing backward shift operator $\varphi(\mathrm{B}), \theta(\mathrm{B})$, equation(8) can be written as:

$$
W_{t}=\nabla \nabla_{11} X_{t} \varphi(\mathrm{B})\left(X_{t}-\mu\right)=\theta(\mathrm{B}) \varepsilon_{t}
$$

Here $X_{t}$ is the annual precipitation in $t^{t h}$ year, $\mathrm{p}=1, \mathrm{q}=1$.

\section{Temperature forecasting}

Despite of the fluctuation, it is reasonable to utilize Grey Model (GM $(1,1))$ to predict the annual average temperature due to its relatively stable change nature.

GM $(1,1)$ is made up of first-order differential equations, containing only one variable.

Reference data column is known as $x^{(0)}=\left(x^{(0)}(1), x^{(0)}(2), \ldots, x^{(0)}(n)\right.$, first-order accumulated generating operation

$$
x^{(0)}=\left(x^{(0)}(1), x^{(0)}(2), \ldots, x^{(0)}(n)\right)
$$

In this formula, $x^{(1)}(k)=\sum_{i=1}^{k} x^{(0)}(i), k=1,2, \ldots, n$. The mean value generating operation $x^{(1)}$ is:

$$
z^{(1)}(k)=0.5 x^{(1)}(k)+0.5 x^{(1)}(k-1), k=2,3, \ldots, n
$$

Grey differential equation is established as

$$
x^{(0)}(k)+a z^{(1)}(k)=b, k=2,3, \ldots, n
$$

Then the corresponding whitening differential equation is

$$
\frac{d x^{(1)}}{d t}+a x^{(1)}(t)=b
$$

Assume $\mathrm{Y}=\left[x^{(0)}(2), x^{(0)}(3), \ldots, x^{(0)}(\mathrm{n})\right]^{T}$ we can gain the estimated value of $u$ accounting for reaching minimum of $\mathrm{J}(\mathrm{u})=(Y-B u)^{T}(Y-B u)$, through Least Squares:

$$
\hat{u}=[\hat{a}, \hat{b}]^{T}=\left(B^{T} B\right)^{-1} B^{T} Y
$$

Solving equation (13), then

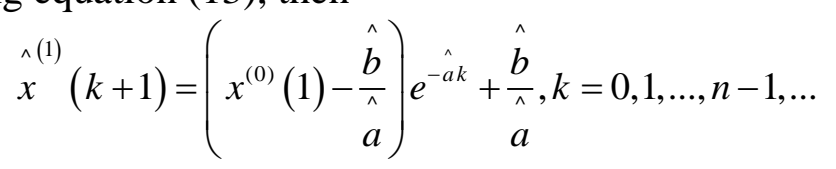

\section{Demand for water}

The water demand consists of industrial, agricultural, residential and environmental need.

\section{Industrial water use}

Facts can be proved that the fluctuation of industrial demand for water is closely associated with the growth of industrial GDP. Industrial water consumptions are supposed to be calculated through the equation below:

$$
\mathrm{I}=\mathrm{W} \times \mathrm{Z}
$$

$\mathrm{Z}$ is industrial added $\operatorname{GDP}\left(10^{4} ¥\right)$, W is the amount of water per $10^{4} ¥$ industrial added GDP.

GDP of Beijing-Tianjin-Hebei region develops with growth rate of 3, of which industrial GDP constitutes around 40 percentage. Thus, the function we get after fitting is

$$
\begin{gathered}
\mathrm{w}=327 /(\mathrm{n}+21.98) \\
\mathrm{I}(n)=G D P_{0}(1+3.3 \%)^{\left(t-t_{0}\right)} \times 327 /(t+21.98)
\end{gathered}
$$




\section{Agricultural water use}

Agricultural need of water (A) can be calculated by multiplying the total cultivated area and the average irrigation water per unit area of this region together.

$$
\mathrm{A}=\mathrm{S} \times \mathrm{a}
$$

S: the total cultivated area of this region, evolves along with per capita GDP.

a : the average irrigation water per unit area of this region.

Agricultural water use in Beijing-Tianjin-Hebei region mainly refers to farmland irrigation water. The farmland area of this region is 98420 thousand $m u\left(1 \mathrm{mu}=666.666 \mathrm{~m}^{2}\right)$. The irrigation volume per $m u$ in Beijing-Tianjin-Hebei region is $164 \mathrm{~m}^{3}$.

There is the following relationship between cultivated land area and per capita GDP:

CA: per capita GDP

$$
\mathrm{S}=1025.3 \times C A^{-0.0092}
$$

\section{Residential water use}

Residential need of water $(\mathrm{R})$ can be calculated by multiplying the total population this year and the residential consumption per capita of this region together.

$$
\mathrm{R}=\operatorname{pop}(\mathrm{t}) \times \mathrm{cap}
$$

$t:$ year

pop $(\mathrm{t})$ : the total population of this region in $t$ year

cap : the residential consumption per capita of this region

The authors found that per capita water consumption is almost constant through research on actual data. To simplify, we take the per capita water consumption as 46 cubic meters.

We use the classic Logistic Population Model to represent and forecast the trend of the population.

r: population growth rate

$$
\mathrm{x}(\mathrm{t})=\frac{x_{m}}{1+\left(\frac{x_{m}}{x_{0}}-1\right) e^{-r t}}
$$

$\mathrm{x}$ : population

$x_{m}$ : the largest population that natural resources and environmental conditions can contain.

\section{Ecological water use}

Ecological water use (E) can be calculated by

$S_{E}$ : afforested area

$$
\mathrm{E}=S_{E} \times a_{E}
$$

$a_{E}$ : Irrigation amount per unit green area

To sum up, total needs of population of this region can be described as follows:

$$
\mathrm{Q}=\mathrm{I}+\mathrm{S} \times \mathrm{a}+\operatorname{pop}(\mathrm{t}) \times \operatorname{cap}+E
$$

Therefore, the ability of a region to provide clean water to meet the needs of its population can be expressed as:

$$
\mathrm{H}=\mathrm{P}-\mathrm{Q}
$$

\section{Analysis of water situation in next 15 years}

By analyzing the relationship between supply and demand, we finish the prediction of water situation of this region. The ability of Beijing-Tianjin-Hebei region to provide clean water to meet needs, which is expressed as variable $\mathrm{H}$, can be described and projected as figure 1 shows. 


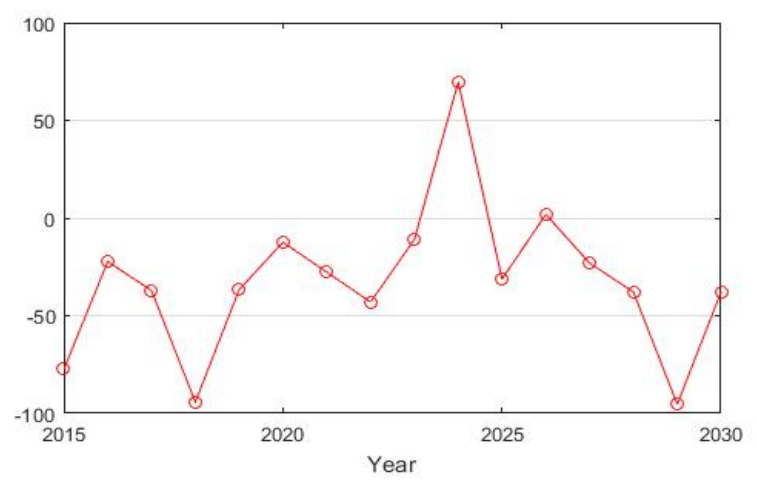

Figure 1: predicted water situation

\section{Summary}

We estimate that the gap between water supply and demand will reach $37.78 \times 10^{8} \mathrm{~m}^{3}$. From the chart we've got, a severe water scarcity will occur in around 2018 and 2029, which is bound to have an impact on people's production and life. $\mathrm{H}$ is negative in most of the time, indicating that it is difficult to meet the demand of population. Consequently, we need to take some measures to balance supply and demand.

\section{References}

[1]Feng Houjun, Qi Chunhua, Xu Ke, Xie Chungang. Problems and Suggestions on Seawater Desalination Technologies and Industry Development in China [J].CHINA WATER\& WASTEWATER, 2015, 12:13-34.

[2]Zhou Hongjun. Chinese Seawater Desalination Industry Development Present Situation and Research [J].OCEAN INFORMATION, 2009, 04:19-23

[3]Zhang Chenjun, Zhang Hengquan. A New Environmental Kuznets Curve: Relationship Between Industrial Water Use and Economic Growth [J].CHINA POPULATION, RESOURCES AND ENVIRONMENT, 2014, 05:116-123.

[4]Hao Lisheng, Min Jinzhong, Liu Keyan. Impact of Climate Change on Hebei Water Resource[J].JOURNAL OF HEBEI NORMAL UNIVERSITY/Natural Science Edition/,2010,04:491-496 